\title{
Pengukuran Kapasitas Container Yard Menggunakan Yard Occupancy Ratio dalam Upaya Optimalisasi Penggunaan Lapangan Penumpukan Kontainer di PT XYZ
}

\author{
Somadi $^{1}$, Intan Dewi Permatasari ${ }^{2}$, Rahmi Chintia $^{3}$ \\ 1,2,3 D-IV Logistik Bisnis, Politeknik Pos Indonesia, Kota Bandung, Indonesia \\ somadi@poltekpos.ac.id ${ }^{1}$, permatasariintan0503@gmail.com ${ }^{2}$, rahmichintia98@gmail.com ${ }^{3}$
}

\section{ARTICLE INFO}

\section{Article History}

Received : 19 January 2020

Reviewed: 10 April 2020

Published: 30 April 2020

Available Online: 30 April

2020

Keywords:

Overcapasity;

Yard Occupancy Ratio;

Forecasting;

Moving Average;

Exponential Smoothing

\begin{abstract}
PT. XYZ is a logistics service company engaged in freight forwarding services for ships / air ships and warehousing. In its operations, the company experienced a problem, namely the flow of containers that entered the company's container yard capacity experienced overcapacity. The purpose of this study was to determine the results of the measurement of container yard capacity using the yard occupancy ratio at PT. XYZ This study uses the Yard Occupancy Ratio (YOR) method to determine the capacity of the container yard, while for forecasting using moving averages and exponential smoothing. Meanwhile, to calculate forecast error using mean squared error and mean absolute percent error. Based on the results of measurements made that the results of forecasting container flows for July 2019 to December 2019 amounted to 1,487 containers, 1,493 containers, 1,614 containers, 1,377 containers, 1,532 containers and 1,495 containers, respectively. Based on the results of the YOR analysis that scenario 3 is the best scenario compared to scenario 1 and scenario 2, because it produces a lower YOR value, namely for July 2019 at 45\%, August 2019 at 45\%, September 2019 at 48\%, October 2019 at 41\%, November 2019 at $46 \%$ and December 2019 at 45\%. This means that by using the YOR method there will be no overcapasity in the future because the YOR value does not exceed $100 \%$.
\end{abstract}

\section{A. PENDAHULUAN}

Pada saat ini tingkat persaingan dalam bisnis semakin ketat dan menuntut perusahaan untuk lebih memperhatikan penanganan dalam hal pengendalian kondisi lapangan untuk menempatkan container guna menjaga lancarnya arus kontainer yang datang dan keluar sehingga tidak terjadi overcapasity di container yard. Container yardmerupakan lapangan untuk mengumpulkan, menyimpan dan menumpuk petikemas, dimana petikemas yang berisi muatan diserahkan ke penerima barang dan petikemas kosong diambil oleh pengirim barang[1].Container yardjuga diartikan sebagai lapangan penumpukan petikemas yang berisi muatan full container load dan petikemas kosong yang akan dikapalkan[2]. Lapangan ini berada di daratan dan permukaannya harus diberi perkerasan untuk dapat mendukung peralatan pengangkut dan beban petikemas. Peti kemas (container)sebagai wadah/gudang, alat angkut yang dilayani oleh Terminal/Pelabuhan Peti Kemas[3].

Untuk terminal petikemas modern,container yard dibagi menjadi petikemasexport/import, refer dan empty.Terminal Peti Kemas berfungsi sebagai transfer area dengan jenis kegiatan yakni tempat pemuatan dan pembongkaran petikemas dari kapal-truk atau sebaliknya, pengepakan dan pembongkaran peti kemas (CFS), pengawasan dan penjagaan peti kemas beserta muatannya, penerimaan armada kapal, dan pelayanan cargo handlingpeti kemas dan lapangan penumpukannya[3]. Untuk itu diperlukan untuk mengukur kinerja terminal peti kemas. Kinerja terminal petikemas sebagai sebuah sistem dengan banyak variabel yang mempengaruhinya guna mengetahui apakah sudah memenuhi syarat untuk melayani arus volume petikemas yang keluar atau masuk[4].

Dengan demikian, untuk mengendalikan kapasitas container yard diperlukan perhitungan pemakaian lapangan untuk penumpukan peti keWamas. Perhitungan pemakaian lapangan untuk penumpukan peti kemas merupakan perbandingan antara pemakaian fasilitas lapangan penumpukan peti kemas dengan kapasitas 
tersedia yang dinyatakan dalam persentase. Tujuan penggunaan lapangan penumpukan peti kemas (yard occupancy ratio) yakni untuk menghitung penggunaan tambatan yang tersedia di suatu pelabuhan[1]. Untuk itu perusahaan perlu melakukan pengendalian perencanaan untuk lapangan kontainer. Hal ini disebabkan apabila perusahaan tidak memperhatikan pengendalian khususnya arus kontainer, maka akan menyebabkan terjadinya overcapacity. Analisis kebutuhan container yard akan berdampak pada upaya peningkatan kapasitas saat ini dan masa mendatang[2].

Dalam pengelolaan container yard perlu adanya perencanaan atau peramalan guna memperkirakan arus kontainer di masa yang akan datang. Peramalan merupakan suatu seni dari ilmu memprediksi sesuatu yang belum terjadi dengan tujuan untuk memperkirakan peristiwa-peristiwa yang akan terjadi di masa depan nantinya dengan selalu memerlukan data-data dari masa lalu[5].Oleh karena itu perlu dilakukan penelitian untuk mengidentifikasi, menghitung kapasitas pada container yard perusahaan dengan menggunakan metode Yard Occupancy Ratio.Dalam penelitian Handajani (2004)bahwa secara keseluruhan kelancaran operasi sangat bergantung pada pelayanan chassis truck di container yard berupa pengaturan pola penumpukan peti kemas di container yard maupun penggunaan rubber tyred gantry secara optimal[6].

PT. XYZ adalah perusahaan jasa logistik yang bergerak di bidang usaha jasa ekspedisi muatan kapal laut/kapal udara (EMKL/EMKU) dan pergudangan yang salah satunya juga adalah penyimpanan peti kemas. PT. XYZ mengalami kendaladalam melakukan proses bisnisnya yaitu terjadinyaovercapasityyang terjadi di lapangan utara container yard. Dengan demikian untuk meningkatkan kepuasan pelayanan kepada konsumen, maka antara arus kontainer baik dariGate Out dan Gate In harus seimbang sehingga tidak melebihi kapasitas yang seharusnya. Namun pada kenyataanya tidak sesuai karena kontainer yang masuk tidak seimbang dengan kontainer yang keluar yang berakibat pada kondisi lapangan yang penuh dan macet pada container yard.Kejadian tersebut dapat merugikan dari pihak perusahaan maupun dari pihak importir serta berdampak pada lamanya waktu pada saat pengeluaran kontainer.Pergerakan kontainer yang terjadi adalah antara shipper (pihak pengekspor), consignee (pihak pengimpor), depot dan pelabuhan[7]. Dengan demikian, tujuan penelitian ini adalah mengetahui hasil pengukuran kapasitas container yard dengan menggunakan yard occupancy ratio di PT. XYZ.

\section{B. METODOLOGI PENELITIAN}

Metode yang digunakan dalam penelitian ini menggunakan pendekatan kuantitatif dengan teknis analisis menggunakan metode Yard Occupancy Ratio (YOR). YOR adalah kuantitas pemakaian lapangan penumpukan container di terminal peti kemas per periode tertentu[8].Pemilihan metode pemecahan masalah didasarkan pada hubungan antara permasalahan yang ada dengan analisis yang terkait dengan overcapasity pada perusahaan.

Lokasi penelitian dilakukan di PT. XYZ pada divisi lapangan utara tempat penimbunan sementara (TPS) yang bertugas sebagai input data Gate In dan Gate Out kontainer.Penelitian ini menggunakan teknik pengumpulan data menggunakan studi dokumentasidan wawancara. Studi dokumentasi digunakan untuk pengumpulan data sekunder, sedangkanwawancara yang dilakukan untuk melengkapi informasi terkait jenis kontainer yang ada, data Gate In dan Gate Out perusahaan, serta cara penumpukan pada container yard. Adapun tahapan-tahapan pada rancangan analisis yang dilakukan antara lain sebagai berikut:

1. Melakukan Peramalan (forecasting)

Dalam melakukan peramalan (forecasting) dalam penelitian ini menggunakan beberapa analisis antara lain yaitu:

\section{a. Metode Peramalan Moving Average (MA)}

Metode rata-rata bergerak tunggal menggunakan sejumlah data aktual permintaan yang baru untukmembangkitkan nilai ramalan untuk permintaan dimasa yang akan datang. Metode ini mempunyai dua sifatkhusus yaitu untuk membuat forecast memerlukan data historis dalam jangka waktu tertentu, semakinpanjang moving average akan menghasilkan moving averages yang semakinhalus[5].

$$
\mathrm{MA}=\frac{\sum_{\mathrm{i}=1}^{\mathrm{n}} \mathrm{Dt}}{\mathrm{n}}
$$

Keterangan :

$\mathrm{n} \quad=$ Jumlah periode yang dipilih

$\mathrm{t}=1 \quad=$ Periode terlama dalam rata-rata $\mathrm{n}$ periode 
$\mathrm{t}=\mathrm{n} \quad=$ Periode yang terbaru

Dt $\quad=$ Demand pada periode ke-i

b. Metode Peramalan Exponential Smoothing (ES)

Metode exponential smoothing adalah suatu prosedur yang mengulang perhitungan secara terus menerus yang menggunakan data terbaru. Setiap data diberi bobot, di mana bobot yang digunakan disimbolkan dengan alpha. Simbol alpha bisa ditentukan secara bebas, yang mengurangi forecast error. Nilai konstanta pemulusan, $\alpha$, dapat dipilih di antara nilai 0 dan 1, karena berlaku: $0<\alpha<1$ [5].

$$
F_{t}=F_{t-1}+\alpha\left(A_{t-1}-F_{t-1}\right)
$$

Keterangan:

$\mathrm{Ft} \quad=$ Peramalan permintaan pada periode $\mathrm{t}$

Ft-1 = Peramalan permintaan pada periode sebelum $\mathrm{t}$

$\alpha \quad=$ Alpha, koefisien "pemulus" $(0<\alpha<1)$

At-1 = Permintaan aktual dalam periode sebelum $\mathrm{t}$

Sementara itu, untuk melakukan perhitungan forecast error menggunakan beberapa analisis antara lain sebagai berikut:

a. $\quad$ Menghitung Mean Squared Error (MSE)

MSE merupakan perhitungan yang digunakan untuk menghitung rata-rata kesalahan berpangkat[5].

$\mathrm{MSE}=\frac{\sum_{i=1}^{n}\left(A_{t}-F_{t}\right)^{2}}{n}$

Keterangan:

$\mathrm{Ft} \quad=$ ramalan permintaan periode $\mathrm{i}$

At $=$ permintaan aktual periode $\mathrm{i}$

$\mathrm{n} \quad=$ jumlah pengamatan (periode waktu)

At-Ft $=$ deviasi (kesalahan peramalan)

b. Mengitung Mean Absolute Percent Error (MAPE)

MAPE merupakan perhitungan yang digunakan untuk menghitung rata-rata persentase kesalahan mut$\operatorname{lak}[5]$.

MAPE $=\frac{100}{\mathrm{n}} \sum_{\mathrm{t}=1}^{\mathrm{n}}\left[\frac{A t-F t}{A t}\right]$

Keterangan:

$\mathrm{Ft} \quad=$ ramalan permintaan periode $\mathrm{i}$

At $=$ permintaan aktual periode $\mathrm{i}$

$\mathrm{n} \quad=$ jumlah pengamatan (periode waktu)

At-Ft $=$ deviasi (kesalahan peramalan)

$|\mathrm{At}-\mathrm{Ft}|=$ deviasi absolut

2. Mengukur Kapasitas CY saat ini dan setelah peramalan

Setelah memperoleh hasil dari peramalan serta forecast eror maka dapat diketahui untuk peramalan dalam jangka waktu pendek dengan data yang ada. Pengukuran kapasitas dapat digunakan menggunakan metode YOR(Yard Occupancy Ratio)[9].Sebelum melakukan penghitungan kapasitas maka perlu menentukan kapasitas yang terpakai dengan rumus sebagai berikut:

$\mathrm{A}=\frac{\mathrm{T} \cdot \mathrm{D} \cdot \mathrm{Sf}}{30-(1-\mathrm{BS})}$

Keterangan:

A = Kapasitas Terpakai

$\mathrm{T}=$ Arus kontainer per bulan (Teus)

$\mathrm{D}=$ Waktu tinggal kontainer (hari)

$\mathrm{Sf}=$ Stowage Factor $(\mathrm{m} 3)$

$\mathrm{BS}=$ Broken Stowage 
Setelah mendapatkan kapasitas yang terpakai dengan menggunakan data yang ada maka dapat digunakan pengukuran kapasitas.

YOR $=\frac{\text { Kapasitas yang terpakai }}{\text { kapasitas yang tersedia }} \times 100 \%$

3. Menggunakan Skema Skenario penyelesaian

Pola scenario merupakan pemikiran sebagai solusi permasalahan yang timbul,dan pola skenario ini ditetapkan berdasarkan hasil perhitungan pada peramalan yang terjadi dan pengukuran kapasitas sehingga diharapkan dapat menjadikan usulan atas masalah yang terjadi sehingga dapat mencegah terjadinya overcapasity dimasa yang akan datang[9].

\section{HASIL DAN PEMBAHASAN}

Berdasarkan data dari pihak perusahaan, diketahui bahwa terdapat data mengenai kontainer yang masuk (Gate In) serta kontainer yang keluar (Gate Out). Dari data tersebut dapat digunakan sebagai dasar pada pelaksanaan analisis.Adapun data yang digunakan adalah data enam bulan kebelakang terhitung dari JanuariJuni 2019 berdasarkan ketersediaan data yang ada di perusahaan. Selain itu juga, data yang digunakan sudah mewakili trend data yang ada di perusahaan. Berikut adalah data Gate In dan Gate Outkontainer :

Tabel 1.GATE OUT dan GATE IN Lapangan Utara

\begin{tabular}{|c|c|c|c|c|c|c|c|c|c|c|c|c|c|}
\hline \multirow{3}{*}{ No } & \multirow{3}{*}{ Bulan } & \multicolumn{6}{|c|}{ Gate out } & \multicolumn{6}{|c|}{ Gate in } \\
\hline & & \multicolumn{3}{|c|}{ Box Utara } & \multicolumn{3}{|c|}{ Teus Utara } & \multicolumn{3}{|c|}{ Box Utara } & \multicolumn{3}{|c|}{ Teus Utara } \\
\hline & & $20^{\prime}$ & $40^{\prime}$ & Jumlah & $20^{\prime}$ & $40^{\prime}$ & Jumlah & $20^{\prime}$ & $40^{\prime}$ & Jumlah & 20 & $40^{\prime}$ & Jumlah \\
\hline 1 & Januari & 1.110 & 1.152 & 2.262 & 1.110 & 2.310 & 3.414 & 994 & 1.213 & 2.207 & 994 & 2.426 & 3.420 \\
\hline 2 & Februari & 754 & 935 & 1.689 & 754 & 1.870 & 2.624 & 730 & 793 & 1.523 & 730 & 1.586 & 2.316 \\
\hline 3 & Maret & 600 & 548 & 1.148 & 600 & 1.096 & 1.696 & 570 & 533 & 1.103 & 570 & 1.066 & 1.636 \\
\hline 4 & April & 624 & 544 & 1.168 & 624 & 1.088 & 1.712 & 615 & 486 & 1.101 & 615 & 972 & 1.587 \\
\hline 5 & Mei & 581 & 623 & 1.204 & 581 & 1.246 & 1.827 & 470 & 611 & 1.081 & 470 & 1.222 & 1.692 \\
\hline 6 & Juni & 196 & 241 & 437 & 196 & 482 & 678 & 519 & 550 & 1.069 & 519 & 1.100 & 1.619 \\
\hline JUI & $\mathrm{LAH}$ & 3.865 & 4.043 & 7.908 & 3.865 & 8.092 & 11.951 & 3.898 & 4.186 & 8.084 & 3.898 & 8.372 & 12.270 \\
\hline
\end{tabular}

Sumber: Hasil Pengolahan Data, Tahun 2020

Dari data Gate Out dan Gate In tersebut maka dapat dilakukan peramalan terhadap 6 bulan kedepan. Peramalan dilakukan agar dapat memperkirakan dalam 6 bulan kedepan terhitung dari bulan JuliDesember2019. Perkiraan atau peramalan permintaan suatu barang atau jasa membutuhkan informasi tentang pola permintaan terhadap barang atau jasa tersebut, dengan mempertimbangkan jenis pola data yang terbentuk maka dapat diketahui metode peramalan yang paling tepat dan cocok untuk digunakan.

Berdasarkan pola data dari Januari-Juni 2019, maka dapat dilakukan peramalan yang bertujuan untuk memperkirakan Gate Out dan Gate In dalam 6 bulan kedepan. Peramalan yang digunakan adalah Moving Average dan Exponential Smoothing. Setelah melakukan peramalan, maka tahap berikutnya yaitu menentukan mean squared error (MSE), mean absolute percent error (MAPE). Alasan penggunaan Exponential Smoothing karena metode ini cocok untuk melakukan peramalan jangka pendek, dan data yang digunakan tidak mengharuskan trend atau pola pertumbuhankonsisten, selain itu diasumsikan data berfluktuasi di sekitar nilai mean yang tetap sehingga memberikan penekanan yang lebih besar kepada time series saat ini melalui penggunaan sebuah konstanta smoothing (penghalus), sedangkan pemiliha metode peramalan Moving Averagedigunakan karena peramalan menggunakan sekelompok nilai pengamatan, dan mencarinilai rataratatersebut sebagai ramalan untuk periode yang akan datang.Untuk melakukan peramalan memerlukan data historis selamajangka waktu tertentu misalnya 3 bulan, apabila semakin panjang jangkawaktu moving average,maka menghasilakan moving average yang semakin halus.

Berdasarkan rumus perhitungan peramalan maka peramalan dapat dilakukan berdasarkan Gate Out dan Gate In kontainer sebagai berikut : 


\section{Gate Out Kontainer Moving Average}

Tabel 2 berikut merupakan tabel perhitungan peramalan Gate Out dengan menggunakan Moving Average.

Tabel 2.Perhitungan Moving Average

\begin{tabular}{|c|c|c|c|c|c|c|}
\hline \multirow{2}{*}{ No } & \multirow{2}{*}{ Bulan } & \multicolumn{5}{|c|}{ Gate Out Kontainer } \\
\hline & & Jumlah & Moving Average 3 Bulan & $\mid$ At-Ft $\mid$ & $(\mathrm{At}-\mathrm{Ft}) 2$ & {$[\{\mathrm{At}-\mathrm{Ft} / \mathrm{At}\}]$} \\
\hline 1 & Januari & 3.414 & - & - & - & - \\
\hline 2 & Februari & 2.624 & - & - & - & - \\
\hline 3 & Maret & 1.696 & - & - & - & - \\
\hline 4 & April & 1.712 & 2.578 & -866 & 749.956 & $-0,506$ \\
\hline 5 & Mei & 1.827 & 2.011 & -184 & 33.733 & $-0,101$ \\
\hline 6 & Juni & 678 & 1.745 & -1.067 & 1.138 .489 & -1.574 \\
\hline Jun & & 11.952 & & -2.117 & 1.922 .178 & -2.180 \\
\hline
\end{tabular}

Sumber: Hasil Pengolahan Data, Tahun 2020

\section{Exponential Smoothing $(\alpha=0,5)$}

Tabel 3 berikut adalah tabel perhitungan peramalan Gate Out dengan menggunakan Exponential Smoothing:

Tabel 3.Perhitungan Exponential Smoothing

\begin{tabular}{|lllllll|}
\hline \multirow{2}{*}{ No } & \multirow{2}{*}{ Bulan } & \multicolumn{6}{l}{ Gate Out Kontainer } & & \\
\cline { 3 - 7 } & & Jumlah & ES $(\alpha=0,5)$ & $\mid$ At-Ft $\mid$ & $($ At-Ft $) 2$ & {$[\{$ At-Ft/At $\}]$} \\
\hline 1 & Januari 2019 & 3.414 & - & - & - & - \\
\hline 2 & Februari 2019 & 2.624 & 3.414 & -790 & 624.100 & $-0,30$ \\
\hline 3 & Maret 2019 & 1.696 & 3.019 & -1.323 & 1.750 .329 & $-0,78$ \\
\hline 4 & April 2019 & 1.712 & 2.160 & -448 & 200.704 & $-0,26$ \\
\hline 5 & Mei 2019 & 1.827 & 1.704 & 123 & 15.129 & 0,07 \\
\hline 6 & Juni 2019 & 678 & 1.770 & -1.092 & 1.191 .372 & $-1,61$ \\
\hline Jumlah & 1.1951 & & -3.530 & 3.781 .634 & $-2,89$ \\
\hline
\end{tabular}

Sumber: Hasil Pengolahan Data, Tahun 2020

Berdasarkan hasil peramalan diatas, dilanjutkan dengan melakukan perhitungan kesalahan peramalan. Dari hasil perhitungan tersebut, dilakukan pembandingan dan didapat hasil penghitungan nilai kesalahan peramalan menggunakan mean squared error(MSE) dan mean absolute percent error(MAPE). Berikut ini adalah hasil penghitungan menggunakan mean squared error (MSE) dan mean absolute percent error (MAPE).

Tabel 4.Perbandingan Peramalan

\begin{tabular}{|lll|}
\hline Metode & Nilai MSE & Nilai MAPE \\
\hline Moving Average Bergerak 3 Bulan & 320.363 & $36,3 \%$ \\
\hline Exponential Smoothing $\alpha=0,5$ & 630.272 & $48,2 \%$ \\
\hline
\end{tabular}

Sumber: Hasil Pengolahan Data, Tahun 2020

Parameter yang digunakan untuk memilih metode terpilih adalah dengan membandingkan hasil error terkecil. Berdasarkan nilai error terkecil, maka perhitungan peramalan Gate Out kontainer yang digunakan adalah moving average, karena memiliki nilai MAPE dengan persentase yaitu 36,3\% lebih kecil dari exponential smoothing dengan persentase $48,2 \%$.

\section{Gate In Kontainer}

\section{Moving Average}

Tabel 5 berikut adalah tabel perhitungan peramalan Gate In dengan menggunakan Moving Average. 
Tabel 5.Perhitungan Moving Average

\begin{tabular}{|lllllll|}
\hline \multirow{2}{*}{ No } & \multirow{2}{*}{ Bulan } & \multicolumn{2}{l}{ Gate In Kontainer } & & \\
\cline { 2 - 7 } & & Jumlah & Moving Average 3 Bulan & $|\mathrm{At}-\mathrm{Ft}|$ & $(\mathrm{At}-\mathrm{Ft}) 2$ & {$[\{\mathrm{At}-\mathrm{Ft} / \mathrm{At}\}]$} \\
\hline 1 & Januari & 3.420 & - & - & - & - \\
\hline 2 & Februari & 2.316 & - & - & - & - \\
\hline 3 & Maret & 1.636 & - & -870 & 757.480 & - \\
\hline 4 & April & 1.587 & 2.457 & -154 & 23.819 & $-0,548$ \\
\hline 5 & Mei & 1.692 & 1.846 & -19 & 374 & $-0,012$ \\
\hline 6 & Juni & 1.619 & 1.638 & -1.044 & 781.673 & $-0,652$ \\
\hline Jumlah & 12.270 & & & & \\
\hline
\end{tabular}

Sumber: Hasil Pengolahan Data, Tahun 2020

\section{Exponential Smoothing $(\alpha=0,5)$}

Tabel 6 berikut adalah tabel perhitungan peramalan Gate Indengan menggunakan exponential smoothing.

Tabel 6.Perhitungan Exponential Smoothing

\begin{tabular}{|c|c|c|c|c|c|c|}
\hline \multirow{2}{*}{ No } & \multirow{2}{*}{ Bulan } & \multicolumn{5}{|c|}{ GATE IN KONTAINER } \\
\hline & & Jumlah & $\mathrm{ES}(\alpha=0,5)$ & $\mid$ At-Ft & $(\mathrm{At}-\mathrm{Ft}) 2$ & {$[\{\mathrm{At}-\mathrm{Ft} / \mathrm{At}\}]$} \\
\hline 1 & Januari 2019 & 3.420 & - & & & \\
\hline 2 & Februari 2019 & 2.316 & 3.420 & -1.104 & 1.218 .816 & $-0,48$ \\
\hline 3 & Maret 2019 & 1.636 & 2.868 & -1.232 & 1.517 .824 & $-0,75$ \\
\hline 4 & April 2019 & 1.587 & 1.976 & -389 & 151.321 & $-0,25$ \\
\hline 5 & Mei 2019 & 1.692 & 1.612 & 81 & 6.480 & 0,05 \\
\hline 6 & Juni 2019 & 1.619 & 1.640 & -21 & 420 & $-0,01$ \\
\hline \multicolumn{2}{|c|}{ Jumlah } & 12.270 & & -2.665 & 2.894 .862 & $-1,44$ \\
\hline
\end{tabular}

Sumber: Hasil Pengolahan Data, Tahun 2020

Berdasarkan hasil peramalan diatas, dilanjutkan dengan melakukan perhitungan kesalahan peramalan. Dari hasil perhitungan tersebut, dilakukan pembandingan dan didapat hasil penghitungan nilai kesalahan peramalan menggunakan Mean Squared Error (MSE) dan Mean Absolute Percent Error (MAPE). Berikut ini adalah rekapitulasi hasil penghitungan moving average dan exponential smoothing.

Tabel 7.Perbandingan Peramalan

\begin{tabular}{|lll|}
\hline Metode & Nilai MSE & Nilai MAPE \\
\hline Moving Average Bergerak 3 Bulan & 130.279 & $10,9 \%$ \\
\hline Exponential Smoothing $\alpha=0,5$ & 482.477 & $24 \%$ \\
\hline
\end{tabular}

Sumber: Hasil Pengolahan Data, Tahun 2020

Parameter yang digunakan untuk memilih metode terpilih adalah dengan membandingkan hasil error terkecil. Berdasarkan nilai error terkecil, maka perhitungan peramalan Gate In kontainer yang digunakan adalah moving average, karena memiliki nilai MAPE dengan persentase 10,9 \% lebih kecil daripada menggunakanexponential smoothing dengan persentase $24 \%$.

Tabel 8 berikut merupakan hasil perhitungan peramalan dengan menggunakan moving average sesuai dengan metode peramalan yang terpilih.

\section{Tabel 8.Hasil Peramalan}

\begin{tabular}{|llll|}
\hline No & Bulan & Jumlah di Gate Out & Jumlah di Gate In \\
\hline 1 & Juli 2019 & 1.406 & 1.633 \\
\hline 2 & Agustus 2019 & 1.417 & 1.650 \\
\hline 3 & September 2019 & 1.276 & 1.630 \\
\hline 4 & Oktober 2019 & 1.523 & 1.640 \\
\hline 5 & November 2019 & 1.366 & 1.638 \\
\hline 6 & Desember 2019 & 1.405 & 1.640 \\
\hline
\end{tabular}

Sumber: Hasil Pengolahan Data, Tahun 2020 


\section{Menghitung Arus Kontainer}

Penghitungan arus kontainer dilakukan apabila terdapat data Gate In danGate Out. Dalam perhitungan arus kontainer yaitu dengan menganggap Gate In sebagai (+) dan Gate Out sebagai (-). Apabila hasil menghasilkan nilainegative (-), maka menunjukkan bahwa kondisi lapangan masih memiiki block yang kosong atau kapasitas yang masih tersedia. Namun apabila menghasilkan positive (+) maka menunjukan bahwa kondisi lapangan penuh atau melebihi dari kapasitas lapangan. Kapasitas lapangan kontainer sendiri di PT. XYZ adalah 1.260 Teus. Tabel 9. merupakan perhitungan arus kontainer lapangan utara PT. XYZ.

Tabel 9.Arus Kontainer

\begin{tabular}{|lllllll|}
\hline No & Bulan & $\begin{array}{l}\text { Jumlah } \\
\text { Out }\end{array}$ & $\begin{array}{l}\text { Gate } \\
\text { In }\end{array}$ & $\begin{array}{l}\text { Inlah Gate } \\
\text { Hasil }\end{array}$ & $\begin{array}{l}\text { Kapasitas } \\
\text { Kontainer }\end{array}$ & $\begin{array}{l}\text { Arus Kontain- } \\
\text { er }\end{array}$ \\
\hline 1 & Januari & 3.414 & 3.420 & 6 & 1.260 & 1.266 \\
\hline 2 & Februari & 2.624 & 2.316 & -308 & 1.260 & 952 \\
\hline 3 & Maret & 1.696 & 1.636 & -60 & 1.260 & 1.200 \\
\hline 4 & April & 1.712 & 1.587 & -125 & 1.260 & 1.135 \\
\hline 5 & Mei & 1.827 & 1.692 & -135 & 1.260 & 1.125 \\
\hline 6 & Juni & 678 & 1.619 & 941 & 1.260 & 2.201 \\
\hline 7 & Juli & 1.406 & 1.633 & 227 & 1.260 & 1.487 \\
\hline 8 & Agustus & 1.417 & 1.650 & 233 & 1.260 & 1.493 \\
\hline 9 & September & 1.276 & 1.630 & 354 & 1.260 & 1.614 \\
\hline 10 & Oktober & 1.523 & 1.640 & 117 & 1.260 & 1.377 \\
\hline 11 & November & 1.366 & 1.638 & 272 & 1.260 & 1.532 \\
\hline 12 & Desember & 1.405 & 1.640 & 235 & 1.260 & 1.495 \\
\hline
\end{tabular}

Sumber: Hasil Pengolahan Data, Tahun 2020

\section{Menghitung Yard Occupancy Ratio (YOR)}

Setelah melakukan penghitungan peramalan selama bulan Juli 2019 sampai dengan bulan Desember 2019 dan sudah menghitung arus kontainer saat ini dan setelah peramalan yang tertera pada tabel 9 . Untuk dwelling time pada perusahaan adalah 6 hari serta jumlah tumpukan kontainer adalah 3 tier. Pada ketentuan penumpukan kontainer terdapat stowage factor dengan tinggi 3 tier adalah sebesar $10 \mathrm{~m} 3$, sedangkan dengan tinggi penumpukan 4 tier adalah sebesar 7,5m3. Pada container yard perusahaan memiliki nilai broken stowage (BS) sebesar 40\%. Tabel 10 berikut merupakan hasil perhitungan kapasitas yang terpakai dan YOR saat ini dan setelah peramalan :

Tabel 10.YOR

\begin{tabular}{|lllllllll|}
\hline Bulan & $\begin{array}{l}\text { Arus } \\
\text { Kontainer }\end{array}$ & D & SF & $\begin{array}{l}\text { Jumlah } \\
\text { Hari }\end{array}$ & BS & A (m2) & $\begin{array}{l}\text { Kapasitas } \\
(\mathrm{m} 2)\end{array}$ & Tersedia \\
\hline Januari 2019 & 1.266 & 6 & 10 & 30 & 0,4 & $2.531,4$ & 2.500 & $101 \%$ \\
\hline $\begin{array}{l}\text { Februari } \\
2019\end{array}$ & 952 & 6 & 10 & 30 & 0,4 & $1.904,4$ & 2.500 & $76 \%$ \\
\hline Maret 2019 & 1.200 & 6 & 10 & 30 & 0,4 & $2.400,4$ & 2.500 & $96 \%$ \\
\hline April 2019 & 1.135 & 6 & 10 & 30 & 0,4 & $2.270,4$ & 2.500 & $91 \%$ \\
\hline Mei 2019 & 1.125 & 6 & 10 & 30 & 0,4 & $2.250,4$ & 2.500 & $90 \%$ \\
\hline Juni 2019 & 2.201 & 6 & 10 & 30 & 0,4 & $4.402,4$ & 2.500 & $176 \%$ \\
\hline Juli 2019 & 1.487 & 6 & 10 & 30 & 0,4 & $2.974,4$ & 2.500 & $119 \%$ \\
\hline $\begin{array}{l}\text { Agustus } \\
2019\end{array}$ & 1.493 & 6 & 10 & 30 & 0,4 & $2.986,4$ & 2.500 & $129 \%$ \\
\hline $\begin{array}{l}\text { September } \\
2019\end{array}$ & 1.614 & 6 & 10 & 30 & 0,4 & $3.228,8$ & 2.500 & $110 \%$ \\
\hline $\begin{array}{l}\text { Oktober } \\
2019\end{array}$ & 1.377 & 6 & 10 & 30 & 0,4 & $2.754,4$ & 2.500 & $123 \%$ \\
\hline $\begin{array}{l}\text { November } \\
2019\end{array}$ & 1.532 & 6 & 10 & 30 & 0,4 & $3.064,4$ & 2.500 & $120 \%$ \\
\hline $\begin{array}{l}\text { Desember } \\
2019\end{array}$ & 1.495 & 6 & 10 & 30 & 0,4 & $2.990,4$ & 2.500 & \\
\hline
\end{tabular}


Nilai YOR sebesar $101 \%$ menunjukan bahwa tingkat penggunaan container yard sedang dalam kondisi yang stabil dan baik, namun pada YOR yang sedang diramalkan memiliki hasil sebesar $129 \%$. Hal itu menunjukan bahwa akan terjadi overcapasity pada masa yang akan datang. Oleh karena itu perlu dilakukan beberapa langkah yang dilakukan guna mengoptimalisasikan kapasitas container yard.

Optimalisasi terhadap kapasitas container yard perusahaan akan dilakukan dengan penerapan skema skenario. Skema skenario ini digunakan sebagai kemungkinan yang dapat di ambil oleh perusahaan untuk mengoptimalisasikan container yard agar dapat mengurangi atau menghilangkan terjadinya overcapasity pada perusahaan. Penentuan skenario ditentukan berdasarkan analisis yang dilakukan pada saat melakukan solusi terbaik terhadap perusahaan. Skema skenario yang direncanakan antara lain sebagai berikut:

a. Skenario 1 : Mengoptimalkan tumpukan kontainer di lapangan dari 3 tier menjadi 4 tier. Apabila diterapkan maka akan merubah stowage factor dari $10 \mathrm{~m} 3$ (3 tier kontainer) menjadi7,5m3 (4 tier kontainer).

Pengoptimalan ini didasarkan berdasarkan asumsi penulis dikarenakan masih dapat digunakan pada penumpukan kontainer berisi maksimal penumpukan yaitu 4 tier. Karena apabila kontainer berisi ditumpuk melebihi 4 tier maka dapat berakibat jatuhnya kontainer dan rusaknya barang yang ada di dalam kontainer karena semakin tinggi kontainer di tumpuk maka kontainer yang berada di atas semakin kencang terkena angin dan dapat mengakibatkan kontainer jatuh.

b. Skenario 2 : Menekan dwelling time pada perusahaan dari 6 hari menjadi 3 hari.

Penekanan dwelling time pada perusahaan dapat dijadikan pilihan berikutnya. Dwelling time merupakan waktu simpan kontainer impor pada container yard. Penekanan ini dapat dilakukan dengan membuat kebijakan dari perusahaan yang menyatakan bahwa maksimal waktu simpan berubah dari 6 hari menjadi 3 hari. Hal ini dikarenakan arus kontainer pada perusahaan terhitung tinggi dan apabila waktu simpan kontainer mencapai 6 hari dapat mengakibatkan overcapasity di masa yang akan datang. Kebijakan ini merupakan saran penulis kepada perusahaan agar dapat memangkas dwelling time pada perusahaan. Dengan mengubah biaya simpan kontainer pada hari ke 4-6 menjadi 3 kali lipat biaya normal. Hal tersebut merupakan kebijakan agar dapat menekan importir supaya mengambil kontainernya lebih cepat. Setelah perusahaan membuat kebijakan tersebut, lalu harus melakukan konfirmasi secara berkala kepada pihak bea cukai dan importir agar dapat diterima dari seluruh pihak eksternal.

c. Skenario 3 : Mengabungkan skenario 1 dan skenario 2.

Dari skenario tersebut, maka dilakukan perhitungan untuk masing-masing scenario untuk mengetahui perubahan dari nilai YOR. Perhitungan disajikan dalam bentuk tabel sebagai berikut:

\section{Skenario 1 :}

Tabel 11 berikut ini merupakan hasil perhitungan skenario 1 dan YOR saat ini dan setelah peramalan.

Tabel 11.Skenario 1

\begin{tabular}{|lllllllll|}
\hline Bulan & $\begin{array}{l}\text { Arus } \\
\text { tainer }\end{array}$ & Kon- & D & Sf & $\begin{array}{l}\text { Jumlah } \\
\text { hari }\end{array}$ & BS & A (m2) & $\begin{array}{l}\text { Kapasitas terse- } \\
\text { dia }(\mathrm{m} 2)\end{array}$ \\
\hline Januari & 1.266 & 6 & 7,5 & 30 & 0,4 & $1.898,4$ & 2.500 & $76 \%$ \\
\hline Februari & 952 & 6 & 7,5 & 30 & 0,4 & $1.427,4$ & 2.500 & $57 \%$ \\
\hline Maret & 1.200 & 6 & 7,5 & 30 & 0,4 & $1.799,4$ & 2.500 & $72 \%$ \\
\hline April & 1.135 & 6 & 7,5 & 30 & 0,4 & $1.701,9$ & 2.500 & $68 \%$ \\
\hline Mei & 1.125 & 6 & 7,5 & 30 & 0,4 & $1.686,9$ & 2.500 & $67 \%$ \\
\hline Juni & 2.201 & 6 & 7,5 & 30 & 0,4 & $3.300,9$ & 2.500 & $132 \%$ \\
\hline Juli & 1.487 & 6 & 7,5 & 30 & 0,4 & $2.229,9$ & 2.500 & $89 \%$ \\
\hline Agustus & 1.493 & 6 & 7,5 & 30 & 0,4 & $2.238,9$ & 2.500 & $90 \%$ \\
\hline September & 1.614 & 6 & 7,5 & 30 & 0,4 & $2.420,4$ & 2.500 & $97 \%$ \\
\hline Oktober & 1.377 & 6 & 7,5 & 30 & 0,4 & $2.064,9$ & 2.500 & $83 \%$ \\
\hline November & 1.532 & 6 & 7,5 & 30 & 0,4 & $2.297,4$ & 2.500 & $92 \%$ \\
\hline Desember & 1.495 & 6 & 7,5 & 30 & 0,4 & $2.241,9$ & 2.500 & $90 \%$ \\
\hline
\end{tabular}

Sumber: Hasil Pengolahan Data, Tahun 2020 
Penerapan skenario 1 adalah mengoptimalisasikan penumpukan kontainer dari 3 tier menjadi 4 tier. Berdasarkan hasil skenario 1, maka terlihat hasil YOR peramalan mengalami penurunan dari YOR proyeksi yaitu bulan Juli 2019, bulan Agustus 2019, dan September 2019, Oktober 2019, November 2019, Desember 2019yakni masing-masing 89\%,90\%,97\%, 83\%,92\% dan 90\%.Pada bulan Juli 2019 sampai dengan Desember 2019 peramalan yang dilakukan dengan menggunakan metode YOR di masa yang akan datang tidak terjadi overcapasity yang ditunjukkan dari nilai YOR yang tidak melebihi $100 \%$ artinya bahwa pada bulan Juli 2019 sampai dengan bulan Desember2019 kondisi lapangan penumpukan peti kemas atau container yard dalam keadaan baik.

\section{Skenario 2 :}

Tabel 12 berikut ini merupakan hasil perhitungan skenario2 dan YOR saat ini dan setelah peramalan.

Tabel 12.Skenario 2

\begin{tabular}{|lllllllll|}
\hline Bulan & Arus Kontainer & D & Sf & $\begin{array}{l}\text { Jumlah } \\
\text { hari }\end{array}$ & BS & A (m2) & $\begin{array}{l}\text { Kapasitas } \\
\text { tersedia }(\mathrm{m} 2)\end{array}$ & YOR \\
\hline Januari & 1.266 & 3 & 10 & 30 & 0,4 & $1.265,4$ & 2.500 & $51 \%$ \\
\hline Februari & 952 & 3 & 10 & 30 & 0,4 & 951,4 & 2.500 & $38 \%$ \\
\hline Maret & 1.200 & 3 & 10 & 30 & 0,4 & $1.199,4$ & 2.500 & $48 \%$ \\
\hline April & 1.135 & 3 & 10 & 30 & 0,4 & $1.134,4$ & 2.500 & $45 \%$ \\
\hline Mei & 1.125 & 3 & 10 & 30 & 0,4 & $1.124,4$ & 2.500 & $45 \%$ \\
\hline Juni & 2.201 & 3 & 10 & 30 & 0,4 & $2.200,4$ & 2.500 & $88 \%$ \\
\hline Juli & 1.487 & 3 & 10 & 30 & 0,4 & $1.487,4$ & 2.500 & $59 \%$ \\
\hline Agustus & 1.493 & 3 & 10 & 30 & 0,4 & $1.493,4$ & 2.500 & $60 \%$ \\
\hline September & 1.614 & 3 & 10 & 30 & 0,4 & $1.614,4$ & 2.500 & $65 \%$ \\
\hline Oktober & 1.377 & 3 & 10 & 30 & 0,4 & $1.377,4$ & 2.500 & $55 \%$ \\
\hline November & 1.532 & 3 & 10 & 30 & 0,4 & $1.532,4$ & 2.500 & $61 \%$ \\
\hline Desember & 1.495 & 3 & 10 & 30 & 0,4 & $1.495,4$ & 2.500 & $60 \%$ \\
\hline
\end{tabular}

Sumber: Hasil Pengolahan Data, Tahun 2020

Berdasarkan hasil skenario 2, maka terlihat hasil YOR peramalan mengalami penurunan dari YOR proyeksi yaitu masing-masing dari bulan Juli 2019, bulan Agustus 2019, bulan September 2019, bulan Oktober 2019, bulan November 2019 dan bulan Desember 2019 yakni masing-masing adalah 59 \%, 60 \%, 65 $\%, 55 \%, 61 \%$ dan $60 \%$. Dengan demikian, peramalan yang dilakukan dengan menggunakan metode YOR di masa yang akan datang tidak terjadi overcapasity yang ditunjukkan dari nilai YOR yang tidak melebihi 100\% artinya bahwa pada bulan Juli 2019-bulan Desember 2019 kondisi lapangan penumpukan peti kemas dalam keadaan baik. Pada skenario 2 menghasilkan penurunan dimana pengurangan dwelling time terjadi dari 6 hari menjadi 3 hari.

\section{Skenario 3 :}

Tabel 13 berikut merupakan hasil perhitungan skenario 3 yang di dapat dari penggabungan skenario 1, 2 dan YOR saat ini dan setelah peramalan :

Tabel 13.Skenario 3

\begin{tabular}{|c|c|c|c|c|c|c|c|c|c|c|}
\hline Bulan & $\begin{array}{l}\text { Arus } \\
\text { tainer }\end{array}$ & Kon- & $\mathrm{D}$ & $\mathrm{Sf}$ & $\begin{array}{l}\text { Jumlah } \\
\text { hari }\end{array}$ & BS & $A(m 2)$ & $\begin{array}{l}\text { Kapasitas } \\
(\mathrm{m} 2)\end{array}$ & tersedia & YOR \\
\hline Januari & 1.266 & & 3 & 7,5 & 30 & 0,4 & 948,9 & 2.500 & & $38 \%$ \\
\hline Februari & 952 & & 3 & 7,5 & 30 & 0,4 & 713,4 & 2.500 & & $29 \%$ \\
\hline Maret & 1.200 & & 3 & 7,5 & 30 & 0,4 & 899,4 & 2.500 & & $36 \%$ \\
\hline April & 1.135 & & 3 & 7,5 & 30 & 0,4 & 850,7 & 2.500 & & $34 \%$ \\
\hline Mei & 1.125 & & 3 & 7,5 & 30 & 0,4 & 843,2 & 2.500 & & $34 \%$ \\
\hline Juni & 2.201 & & 3 & 7,5 & 30 & 0,4 & $1.650,2$ & 2.500 & & $66 \%$ \\
\hline Juli & 1.487 & & 3 & 7,5 & 30 & 0,4 & $1.115,7$ & 2.500 & & $45 \%$ \\
\hline Agustus & 1.493 & & 3 & 7,5 & 30 & 0,4 & $1.120,2$ & 2.500 & & $45 \%$ \\
\hline
\end{tabular}




\begin{tabular}{|c|c|c|c|c|c|c|c|c|c|c|}
\hline Bulan & $\begin{array}{l}\text { Arus } \\
\text { tainer }\end{array}$ & Kon- & D & $\mathrm{Sf}$ & $\begin{array}{l}\text { Jumlah } \\
\text { hari }\end{array}$ & BS & $A(m 2)$ & $\begin{array}{l}\text { Kapasitas } \\
\text { (m2) }\end{array}$ & tersedia & YOR \\
\hline September & 1.614 & & 3 & 7,5 & 30 & 0,4 & $1.210,9$ & 2.500 & & $48 \%$ \\
\hline Oktober & 1.377 & & 3 & 7,5 & 30 & 0,4 & $1.033,2$ & 2.500 & & $41 \%$ \\
\hline November & 1.532 & & 3 & 7,5 & 30 & 0,4 & $1.149,4$ & 2.500 & & $46 \%$ \\
\hline Desember & 1.495 & & 3 & 7.5 & 30 & 0,4 & $1.121,7$ & 2.500 & & $45 \%$ \\
\hline
\end{tabular}

Sumber: Hasil Pengolahan Data, Tahun 2020

Berdasarkan hasil skenario 3 merupakan gabungan dari skenario 1 dan 2 terlihat hasil YOR peramalan mengalami penurunan dari YOR proyeksi yakni bulan Juli 2019, bulan Agustus 2019, bulan September 2019,bulan Oktober 2019, bulan November 2019 dan bulan Desember 2019masing-masing adalah 45 \%, 45 $\%, 48 \%, 41 \%, 46 \%$ dan 45\%. Pada bulan Juli 2019 sampai dengan Desember 2019 peramalan yang dilakukan dengan menggunakan metode YOR di masa yang akan datang tidak terjadi overcapasity yang ditunjukkan dari nilai YOR yang tidak melebihi 100\% artinya bahwa pada bulan Juli 2019 sampai dengan bulan Desember 2019 kondisi lapangan penumpukan peti kemas atau container yard dalam keadaan baik.

\section{Perbandingan Hasil YOR Berdasarkan Masing-Masing Scenario}

Tabel 14 berikut merupakan perbandingan hasil perhitugan YOR Berdasarkan Masing-Masing Scenario yang telah dilakukan

\section{Tabel 14.Perbandingan Hasil YOR Berdasarkan Masing-Masing Scenario}

\begin{tabular}{|llll|}
\hline Bulan & Scenario 1 & Scenario 2 & Scenario 3 \\
\hline Januari & $76 \%$ & $51 \%$ & $38 \%$ \\
\hline Februari & $57 \%$ & $38 \%$ & $29 \%$ \\
\hline Maret & $72 \%$ & $48 \%$ & $36 \%$ \\
\hline April & $68 \%$ & $45 \%$ & $34 \%$ \\
\hline Mei & $67 \%$ & $45 \%$ & $34 \%$ \\
\hline Juni & $132 \%$ & $88 \%$ & $66 \%$ \\
\hline Juli & $89 \%$ & $59 \%$ & $45 \%$ \\
\hline Agustus & $90 \%$ & $60 \%$ & $45 \%$ \\
\hline September & $97 \%$ & $65 \%$ & $48 \%$ \\
\hline Oktober & $83 \%$ & $55 \%$ & $41 \%$ \\
\hline November & $92 \%$ & $61 \%$ & $46 \%$ \\
\hline Desember & $90 \%$ & $60 \%$ & $45 \%$ \\
\hline
\end{tabular}

Sumber: Hasil Pengolahan Data, Tahun 2020

Dengan demikian, peramalan yang dilakukan dengan menggunakan metode YOR di masa yang akan datang tidak terjadi overcapasity yang di tunjukan dari nilai YOR yang tidak melebihi 100\%, artinya bahwa pada bulan Juli 2019 sampai dengan bulan Desember 2019kondisi lapangan penumpukan peti kemas dalam keadaan baik baik pada scenario 1, scenario 2 dan scenario 3. Hasil nilai YOR berdasarkan scenario 3 menghasilkan nilai yang lebih rendah dibandingkan scenario 1 dan scenario 2, kemudian pada scenario 3 juga ada asumsi pemangkasan waktu simpan menjadi 3 hari dari lama waktu simpan sebelumnya yakni 6 hari. Sehingga scenario 3 bisa menjadi usulan bagi perusahaan untuk bahan mengambil kebijakan. Apabila perusahaan menggunakan scenario 1 walaupun nilai YOR masih di bawah angka 100\%, namun akan mengakibatkan overcapasity di masa yang akan datang karena arus kontainer tinggi dan waktu simpan kontainer mencapai 6 hari. Sehingga perlu adanya kebijakan untuk memangkas waktu simpan.Sedangkan apabila menggunakan scenario 2, meskipun ada kebijakan dari perusahaan ada pemangkasan waktu simpan yang menyatakan bahwa maksimal waktu simpan berubah dari 6 hari menjadi 3 hari. Namun nilai YOR pada scenario 2 yang diperoleh masih tinggi dibandingkan nilai YOR yang dihasilkan oleh scenario 1, namun lebih rendah dibandingkan dengan nilai YOR yang dihasilkan pada scenario 3.

\section{KESIMPULAN}

Berdasarkan pengolahan data dan analisis yang telah dilakukan terkait pengukuran kapasitas lapangan utara container yard dengan menggunakan metode yard occupancy ratio(YOR) pada PT. XYZ, dapat disimpulkan bahwa hasil peramalan arus kontainer dalam 6 bulan kedepan yakni bulan Juli 2019 sampai dengan 
bulan Desember 2019 yakni masing-masing sebesar 1.487 kontainer, 1.493 kontainer, 1.614 kontainer, 1.377 kontainer, 1.532 kontainer dan 1.495 kontainer. Berdasarkan hasil analisis YOR, bahwa scenario terpilih yakni scenario 3 karena menghasilkan nilai yang lebih rendah dibandingkan dengan nilai scenario 1 dan scenario 2. Adapun hasil YOR dengan menggunakan skenario 3, masing-masing peramalan dari bulan Juli sampai dengan bulan Desember 2019 yakni adalah 45\%, 45\%, 48\%, 41\%, 46\% dan 45\%. Dengan demikian bahwa peramalan dengan menggunakan metode YOR di masa yang akan datang tidak terjadi overcapasity. Hal itu ditunjukkan dari nilai YOR yang tidak melebihi 100\%, artinya bahwa pada bulan Juli 2019 sampai dengan bulan Desember 2019 kondisi lapangan penumpukan peti kemas dalam keadaan baik. Dengan menggunakan skenario 3 yang merupakan gabungan dari skenario 1 dan scenario 2 menghasilkan YOR yang cukup signifikan sehingga skenario 3 merupakan pilihan skenario terbaik dibandingkan skenario 1 dan skenario 2, serta dapat dijadikan sebagai bahan pertimbangan bagi perusahaan untuk membuat kebijakan.

Adapun rekomendasi kepada perusahaan yakni perusahaan diharapkan dapat memperkirakan dalam jangka pendek maupun jangka panjang terhadap arus kontainer yang ada baik dari gate in kontainer dan gate out kontainer sehingga tidak terjadi over capasity pada container yard perusahaan, dan perusahaan diharapkan selalu melakukan update YOR pada container yard sehingga dapat terus memantau kapasitas kontainernya.Bagi peneliti selanjutnya diharapkan menambah periode data yang digunakan agar hasil forecasting lebih akurat.

\section{DAFTAR PUSTAKA}

[1] Y. Fetriansyah and H. K. Buwono, "Analisis Kebutuhan Lapangan Penumpukan (Container Yard) Pada Pelabuhan Pulau Baai Bengkulu," in Seminar Nasional Sains dan Teknologi, 2019, pp. 1-8.

[2] S. K. Aryandi and H. Widyastuti, "Analisis Kebutuhan Container Yard Terminal Multipurpose Teluk Lamong," J. Tek. POMITS, vol. 1, no. 1, pp. 1-6, 2015.

[3] D. Wahono, "Terminal Petikemas pada Pelabuhan Internasional Pantai Kijing di Kecamatan Sungai Kunyit Kabupaten Pontianak,” J. Online Mhs. Arsit. Univ. Tanjungpura, vol. 3, no. 1, pp. 37-55, 2015.

[4] Supriyono, "Analisa Kinerja Terminal Petikemas di Tanjung Perak Surabaya (Study Kasus: PT. Terminal Petikemas Surabaya)," J. MKTS J. Ilm. dan Teraoan Bid. Tek. Sipil, vol. 19, no. 1, pp. 89-97, 2013.

[5] M. A. Maricar, "Analisa Perbandingan Nilai Akurasi Moving Average dan Exponential Smoothing untuk Sistem Peramalan Pendapatan pada Perusahaan XYZ,” J. Sist. dan Inform., vol. 13, pp. 36-45, 2019.

[6] M. Handajani, "Analisis Kinerja Operasional Bongkar Muat Peti Kemas Pelabuhan Tanjung Emas Semarang," J. Transp., vol. 4, no. 1, pp. 1-12, 2004.

[7] W. Sahputra, "Optimasi Pergerakan Kontainer Kosong Menggunakan Model Empty Container Reuse Di Kota Pontianak," Fakultas Teknik, Universitas Tanjungpura, 2015.

[8] D. N. Anggrahini, Karnowahadi, and Paniya, "Pengaruh Yor Dan Total Bor Terhadap Kinerja Operasional Pada PT Pelindo III (Persero) Terminal Petikemas Semarang Pengaruh Yor Dan Bor Terhadap Kinerja Operasional Pada PT Pelindo III (Persero) Terminal Petikemas Semarang," Admisi \& Bisnis, vol. 19, no. 1, pp. 69-78, 2018.

[9] A. Purnomo, S. Widodo, and K. Erwan, "Analisis Kapasitas Terminal Peti Kemas Pelabuhan Pontianak," 2015. 